\title{
Editorial
}

\section{What is general medicine?}

\section{Satoshi Iwase ${ }^{1^{*}}$}

${ }^{1}$ Department of Physiology, Aichi Medical University, Aichi, Japan

What is "general medicine? The definition is difficult, but some defines as "general and internal medicine, of which pathogenesis, epidemiology, diagnosis, monitoring and treatment protocols".

However, in Japan, "general medicine" has a special meaning. There is a TV program of "Doctor G" in Japan. It is like a TV drama "Dr. House" in the United States. At first, a patient enters with complicated complaints. "Doctor General" examines the patient, beginning with the history taking, physical examination, and tells the findings. Yes, "general medicine" is "detective mystery" played by a physician and the patient. In the program, three residents appear and answers the differential diagnosis.
After neurology residency, I entered clinical neurophysiology research, where I learned various kinds of pathophysiology of the disease by teaching "physiology" to the students. This experience provided me a logical thinking in the diagnosis of the disease, not only the field of neurology but also general medicine.

I believe this kind of training is necessary for the residents before determining the subspecialty of internal medicine. This journal will help the residents who always fight with diseases of wide ranges. I hope every medical student as well as residents will read this journal through with a confident mind of the diagnosis and treatment of the wide-ranged malaises.
Copyright: (C2017 Iwase S. This is an open-access article distributed under the terms of the Creative Commons Attribution License, which permits unrestricted use, distribution, and reproduction in any medium, provided the original author and source are credited.
Correspondence to: Satoshi Iwase, Professor, Department of Physiology, Aichi Medical University Yazako-Karimata 1-1, NAGAKUTE 480-1195, Aichi, Japan, Tel: +81 56162 3311; E-mail: s_iwase@nifty.com

Received: May 22, 2017; Accepted: May 24, 2017; Published: May 26, 2017 